\title{
Enhanced dermal delivery of diflucortolone valerate using lecithin/chitosan nanoparticles: in-vitro and in-vivo evaluations
}

This article was published in the following Dove Press journal:

International Journal of Nanomedicine

29 January 2013

Number of times this article has been viewed

\section{İpek Özcan \\ Erkan Azizoğlu \\ Taner Șenyiğit \\ Mine Özyazıcı \\ Özgen Özer}

Ege University, Faculty of Pharmacy, Department of Pharmaceutical

Technology, Bornova, Izmir, Turkey
Correspondence: İpek Özcan Ege University, Faculty of Pharmacy, Department of Pharmaceutical Technology, 35I00, Bornova, Izmir, Turkey

Tel +90232 3III 368

Fax +902323885258

Email ipek.ozcan@ege.edu.tr
Abstract: The objective of this study was to prepare a suitable formulation for dermal delivery of diflucortolone valerate (DFV) that would maintain the localization in skin layers without any penetration and to optimize efficiency of DFV. Drug-loaded lecithin/chitosan nanoparticles with high entrapment efficiency ( $86.8 \%$ ), were successfully prepared by ionic interaction technique. Sustained release of DFV was achieved without any initial burst release. Nanoparticles were also incorporated into chitosan gel at different ratios for preparing a more suitable formulation for topical drug delivery with adequate viscosity. In ex-vivo permeation studies, nanoparticles increased the accumulation of DFV especially in the stratum corneum + epidermis of rat skin without any significant permeation. Retention of DFV from nanoparticle in chitosan gel formulation $(0.01 \%)$ was twofold higher than commercial cream, although it contained ten times less DFV. Nanoparticles in gel formulations produced significantly higher edema inhibition in rats compared with commercial cream in in-vivo studies. Skin blanching assay using a chromameter showed vasoconstriction similar to that of the commercial product. There were no barrier function changes upon application of nanoparticles. In-vitro and in-vivo results demonstrated that lecithin/chitosan nanoparticles in chitosan gel may be a promising carrier for dermal delivery of DFV in various skin disorders.

Keywords: skin permeation, anti-inflammatory activity, skin blanching, TEWL

\section{Introduction}

Steroids are a class of drugs that are commonly used in the treatment of many diseases. Topical corticosteroids, first experienced in clinical practice in the early 1950s, are widely used for skin disorders that require steroid therapy for anti-inflammatory and immunosuppressive purposes; yet the adverse effects of steroids significantly limit their usage since long-term treatment is required in such diseases. ${ }^{1,2}$ Due to skin atrophy, steroid acne, hypopigmentation, transepidermal water loss (TEWL) increase, epidermal thinning, and allergic contact dermatitis that may arise during treatment, the actual dose must be precisely adjusted so that the ratio of benefit/risk should be clearly identified. ${ }^{3}$

The physicochemical characteristics of the drug, the type of vehicle, and the physiological conditions of the skin can significantly affect percutaneous absorption. ${ }^{4,5}$ An important point to consider in the treatment of skin disorders with steroids is the permeation of these molecules to systemic circulation through the skin layers. Permeation of topical drugs through the skin, leading to uptake into the systemic circulation, is generally not desired and may lead to systemic side effects of topical treatments. As an example, topical corticosteroids, besides their well known local side effects, may have systemic adverse effects such as hypothalamic-pituitary-adrenal 
axis suppression, Cushing's syndrome, femoral head osteonecrosis, and cataracts. ${ }^{6,7}$ Several formulation approaches have been developed for topical administration of steroids, such as creams, ointments, lotions, micelles, submicron emulsions, liposomes, solid lipid and polymeric nanoparticles, which include conventional and novel delivery systems. These formulations have been proposed to increase percutaneous absorption of therapeutic agents as well as reducing the damage to the skin barrier function. ${ }^{8-11} \mathrm{~A}$ desired formulation for this purpose should ideally be able to pass through the stratum corneum (SC) and be able to maintain therapeutically relevant concentrations in the epidermis/dermis, without high serum levels and systemic exposure.

Colloidal drug-carrier systems such as nanoparticles, micelles, and liposomes can be classified as the most promising drug-delivery systems for targeting steroids to the skin layers, especially to the viable epidermis layer where antiinflammatory reactions take place. At this point, a significant example for this perspective are the nanoparticles which may alter the flux, provide drug deposition, localization, and even selectively permeabilize the SC. ${ }^{12,13}$ As a result of these properties, nanotechnology systems may allow consecutive and long-term administration of steroidal drugs to the target tissue and improve the pharmacokinetics by optimizing the necessary dose for treatment.

Lecithin is a natural lipid mixture of phospholipids and biocompatible excipient and is frequently used for the preparation of various nanoparticulate delivery systems. ${ }^{14}$ Chitosan, $\operatorname{poly}(\beta$ - $(1,4)$-2-amino-2-deoxy-D-glucose), is one of the major polymers used in pharmaceutical dosage forms. Chitosan is obtained by the alkaline deacetylation of chitin, which exists in the natural structure of crustacean exoskeletons. The outstanding properties that makes chitosan so popular in the pharmaceutical field are its being nontoxic and potentially safe, its biodegradability, and its biocompatibility. ${ }^{15}$ In the literature, nanoparticles have been obtained from the supramolecular self-organizing interaction of negatively charged lipid material lecithin and the positively charged polysaccharide chitosan, without preliminary vesicle formation. ${ }^{16-18}$

Diflucortolone valerate (DFV) is a potent corticosteroidal molecule which is commonly used in the treatment of skin disorders. According to the corticosteroidal classification system, DFV is classified as a high potent steroid for the available formulations of ointments and creams. However depending on its potency, many side effects are observed with respect to the other members of the steroid drugs. ${ }^{19}$

Effectiveness of topical corticosteroids is related to their vasoconstrictive, anti-inflammatory, immunosuppressive, and antiproliferative effects in the treatment of psoriasis and atopic dermatitis. ${ }^{20,21}$ The skin blanching assay has been used in many studies depending on the direct correlation between corticosteroid-induced skin blanching and vasoconstriction. The efficacies of various formulations have been compared with each other as an indicator of the potency of the drug or efficacy of the delivery vehicle. Although a visual parameter, the quantification by chromameter for the exact determination of degree of skin blanching is a new combination technique, which is also used in this study. ${ }^{22}$

Therefore, this study was constructed on two major goals: one was to develop nanoscale formulations of DFV using lecithin/chitosan nanoparticles; and the second was to optimize its efficacy by designing a formulation which can be used safely with minimized potential adverse effects. The optimized nanoparticles were then incorporated into chitosan gels at different ratios in order to enhance the permeation and retention of DFV in skin, in comparison with commercial cream and chitosan gel formulations containing $0.1 \%$ DFV. For this purpose, in-vitro release, ex-vivo permeation, antiinflammatory activity, skin blanching assay, and TEWL measurements were investigated throughout this study.

\section{Materials and methods Materials}

DFV was kindly gifted from Roche, Turkey. Lecithin (Lipoid S45) and chitosan (Chitoclear FG, specifications: molecular weight [MW] $140 \mathrm{kDa}$, deacetylation degree 95\%, viscosity $93 \mathrm{cP}$ for $1 \% \mathrm{w} / \mathrm{v}$ solution in $1 \% \mathrm{v} / \mathrm{v}$ acetic acid) were purchased from Lipoid AG (Ludwigshafen, Germany) and Primex (Haugesund, Norway), respectively. Medium MW chitosan (specifications: MW 190-310 kDa, deacetylation degree $75 \%-85 \%$, viscosity $200-800 \mathrm{cP}$ for $1 \% \mathrm{w} / \mathrm{v}$ solution in $1 \% \mathrm{v} / \mathrm{v}$ acetic acid) for the preparation of gel formulation was obtained from Sigma-Aldrich (St Louis, MO, USA). Polyethylene glycol 400 (PEG-400) was provided by Merck KGaA (Darmstadt, Germany). The commercial product of DFV (Temetex ${ }^{\circledR}$ cream) was used as the control formulation. All other chemicals were of analytical grade.

\section{Preparation of nanoparticles}

The nanoparticles of lecithin/chitosan were prepared according to the method previously reported by Sonvico et al, ${ }^{17}$ via direct injection of soybean lecithin alcoholic solution into aqueous chitosan solution. In this method, the nanoparticles were obtained from the supramolecular self-organizing interaction of negatively charged lipid material lecithin and the positively charged polysaccharide chitosan, without 
preliminary vesicle formation. Briefly, two different types of nanoparticle formulations were prepared. The only difference between these two formulations was the existence of isopropyl myristate (IPM) in the formulation, keeping all the other steps the same. For this purpose, $4 \mathrm{~mL}$ of ethanolic solution containing lecithin $(2.5 \% \mathrm{w} / \mathrm{v})$, drug $(0.1 \%)$, and IPM $(2 \%)$ was prepared. Under mechanical stirring, this solution was rapidly injected (rate of $40 \mathrm{~mL} / \mathrm{min}$ ) into $46 \mathrm{~mL}$ of chitosan solution, which was prepared by dilution of $0.5 \mathrm{~mL}$ of $1 \%$ chitosan solution in $0.275 \mathrm{~N} \mathrm{HCl}$. In the colloidal suspension, lecithin/chitosan was in the ratio of 20:1 (w/w). The same procedure was employed for the formation of blank nanoparticles either with or without IPM.

\section{Characterization of nanoparticles}

\section{Size and zeta potential measurements} of nanoparticles

Particle size and zeta potential of the nanoparticle formulations were measured by dynamic laser light scattering method with Malvern NanoZS (Malvern Instruments, Malvern, UK) at $25^{\circ} \mathrm{C}$. For these measurements, material and dispersant refractive indexes were used as 1.365 and 1.330 , respectively (viscosity $0.8872 \mathrm{cP}$; and dielectric constant 78.547). Results were expressed in terms of mean \pm standard error values after six consecutive measurements.

\section{Entrapment efficiency}

Drug-loaded nanoparticles were centrifuged at $3000 \times g$ for 10 minutes, the sediment was dissolved in ethanol, and the amount of the possible existing DFV, which was precipitated in the preparation process, was assayed. Then, the suspension was ultra-centrifuged at $150000 \times g$ for 2 hours to separate the free drug from encapsulated drug. The clear fluid under the nanoparticle layer was recovered and assayed for dissolved DFV. The amount of DFV in the samples was quantified by high performance liquid chromatography (HPLC) (Agilent 1100 , Germany) system using a reverse phase column $\left(\mathrm{C}_{18}\right.$; $250 \mathrm{~mm} \times 4.6 \mathrm{~mm})$, acetonitrile/water $(55: 45)$ as mobile phase with a flow rate of $1.5 \mathrm{~mL} / \mathrm{min}$. The ultraviolet detection wavelength was set at $240 \mathrm{~nm}$. The entrapment efficiency and drug-loading capacity values were calculated using equations (1) and (2) below:

\section{Morphology of nanoparticles}

The morphology of nanoparticles was examined by Libra 120 transmission electron microscope (TEM) (Carl Zeiss, Oberkochen, Germany). The sample was stained with $2 \%$ w/v uranyl acetate solution for 20 seconds, immobilized on a copper grid coated with Formvar ${ }^{\circledR}$, and dried for viewing by TEM.

\section{Differential scanning calorimetry (DSC) analysis}

DSC measurements of pure drug, blank nanoparticles, physical mixture of drug and blank nanoparticles and drug-loaded nanoparticles were carried out using Perkin Elmer, DSC8000. Measurements were performed at a flow rate of $50 \mathrm{~mL} / \mathrm{min}$ and evaluated within a range of -50 to $300^{\circ} \mathrm{C}$.

\section{In-vitro drug release}

The in-vitro release of DFV from the nanoparticles was carried out using dialysis membrane method. Nanoparticle suspension equivalent to $1 \mathrm{mg}$ drug entrapped was transferred in dialysis bags with a molecular mass cutoff of $12,000 \mathrm{Da}$. The bags were suspended in $20 \mathrm{~mL}$ of ethanol: phosphate buffer saline (PBS) (pH 7.2) at the ratio of $3: 7(\mathrm{v} / \mathrm{v})$ at $37^{\circ} \mathrm{C} \pm 0.5^{\circ} \mathrm{C}$ in a shaking water bath at $100 \mathrm{rpm}$. At predetermined time intervals, aliquots were withdrawn, and the amount of drug was quantified by the abovementioned HPLC method.

\section{Preparation of chitosan gel formulations}

Blank chitosan gel in water was prepared by dissolving $2 \mathrm{~g}$ of chitosan in $100 \mathrm{~mL}$ of acetic acid $1.5 \% \mathrm{w} / \mathrm{v}$ water solution. To prepare the chitosan gel containing pure $\mathrm{DFV}$, the drug was dissolved at a concentration of $10 \%$ (w/w) in PEG-400, and afterwards it was added into the chitosan gel with continuous stirring until a homogenous dispersion was obtained. The final concentration of DFV was $0.1 \%(\mathrm{w} / \mathrm{w})$. Nanoparticle dispersions with and without DFV were incorporated into the blank chitosan gel at three different ratios: 1:1, 1:3, and 1:9 (nanoparticle: gel ratio by weight).

$$
\begin{gathered}
\text { Entrapment efficiency }(\%)=\left[\frac{\text { Total amount of DFV }-(\text { Amount of the precipitated }+ \text { dissolved DFV })}{\text { Total amount of DFV }}\right] \times 100 \\
\text { Drug loading }(\%)=\left[\frac{\text { Total amount of DFV }-(\text { Amount of the precipitated }+ \text { dissolved DFV })}{\text { Total amount of formulation components }}\right] \times 100
\end{gathered}
$$




\section{Characterization of chitosan gel formulations}

\section{$\mathrm{pH}$ measurements}

Direct measurements of formulations were made using a digital pH-meter (Model pHI 71; Beckman Coulter, Brea, CA, USA).

\section{Rheological analysis}

The rheological properties of formulations were characterized by using a HAAKE rheometer (HAAKE MARS Modulars Advanced Rheometer Systems; Thermo Fisher Scientific, Waltham, MA, USA) in flow mode and in conjunction with parallel steel plate geometry $(35 \mathrm{~mm}$, gap $0.3 \mathrm{~mm})$. Oscillatory analysis of each formulation under examination was performed after determination of its linear viscoelastic region, and frequency sweep analysis was performed over the frequency range of $0.1-10.0 \mathrm{~Hz}$ following application of a constant stress. Each measurement was repeated three times, and then the storage modulus $\left(G^{\prime}\right)$ and loss modulus $\left(G^{\prime}\right)$ were determined using HAAKE RheoWin software (Thermo Fisher Scientific).

\section{Mechanical characterization of gel formulations}

Mechanical properties (hardness, adhesiveness, cohesiveness, compressibility, and elasticity) of the formulations were determined using a texture analyzer (TA.XTplus; Stable Micro Systems, Godalming, Surrey, UK) equipped with 5 kg of load cell in texture profile analysis mode. Beakers were filled with the formulation and the analytical probe (Perspex, $10 \mathrm{~mm} / 150 \mathrm{~mm}$; diameter/length) was compressed twice into each sample to a depth of $15 \mathrm{~mm}$ at a rate of $2 \mathrm{~mm} / \mathrm{s}$. A delay period of 15 seconds was allowed between the end of the first and the beginning of the second compression. All analyses were performed at least in triplicate at ambient temperature and fresh sample used in each case. Data collection and calculation were performed using the Texture Exponent 3.0.5.0 software package of the instrument. From the resultant force-time plot, mechanical parameters were defined. ${ }^{23}$

\section{Stability of formulations}

All formulations were stored at $25^{\circ} \mathrm{C}$ and $60 \%$ relative humidity (TK 252 Test Cabinet; Nüve, Ankara, Turkey) in capped glass vials for a period of 3 months. Samples were withdrawn at scheduled time points $(10,30,60$, and 90 days) and analyzed in terms of all characterization properties.

\section{Skin permeation experiments}

The ex-vivo permeation experiments of DFV from nanoparticles, gel formulations, and commercial formulation were performed using Franz-type diffusion cells across rat abdominal skin. Receptor compartment $(5 \mathrm{~mL})$ was composed of a mixture of ethyl alcohol: $\mathrm{PBS}$ at $\mathrm{pH} 7.2$ in the ratio of $3: 7(\mathrm{v} / \mathrm{v})$. This compartment was constantly kept at $37^{\circ} \mathrm{C} \pm 0.5^{\circ} \mathrm{C}$ throughout the experiments. The available diffusion area between donor and receptor compartments was $0.63 \mathrm{~cm}^{2}$. Infinite dose regimen was applied in all experiments. Samples of $300 \mu \mathrm{L}$ were withdrawn from the receptor compartment at specified time intervals and immediately replaced with the same volume of fresh solution to maintain sink conditions.

At the end of the 6-hour permeation experiments, the excess amount of formulation was removed and $\mathrm{SC}+$ epidermis layers were separated from dermis with heat application. The drug was extracted from skin layers using acetonitrile/water (60:40) mixture under sonication for 15 minutes. The amount of DFV in the permeation medium and accumulated in the skin layer sample was determined by the HPLC method. Skin concentration of DFV was calculated by normalizing the amount of drug recovered in the $\mathrm{SC}+$ epidermis and dermis by the weight of tissues and expressed as $\mu \mathrm{g}$ of drug per mg of tissue. All experiments were done in six replicates.

The enhancement ratio was also calculated, to demonstrate the accumulation capacity of lecithin/chitosan nanoparticles for DFV, by dividing the amount accumulated with the test formulation (Q-test) by the amount accumulated with the commercial cream (Q-cream).

\section{In-vivo studies}

Male albino Wistar rats weighing 180-220 g were used for the in-vivo studies. The animals were housed in standard environmental conditions and fed with standard rodent diet with water ad libitum. The experimental protocol was approved by the Local Animal Ethical Committee of Dokuz Eylul University (Approval No 12/2009). In-vivo studies were carried out with commercial cream, selected nanoparticle in gel formulation of DFV and chitosan gel. Their anti-inflammatory, skin blanching activities and TEWL measurements were performed.

\section{Anti-inflammatory activity studies}

The formulations were evaluated for their anti-inflammatory activity using a carrageenan-induced rat paw edema model. ${ }^{24}$ Inflammation was introduced in rats under anesthesia by using $100 \mu \mathrm{L}$ of a $1 \%(\mathrm{w} / \mathrm{v}) \lambda$-carrageenan (Sigma-Aldrich) solution in saline. The solution was injected into the plantar surface of the left hind paw of the rats. The contra-lateral paw received the same volume of sterile saline. To evaluate the topical anti-inflammatory activity of the formulations, 
four groups of animals $(n=6)$ with carrageenan-induced paw edema were examined. An initial group of rats was used as a control (untreated), and they received only the carrageenan solution. Formulations were applied to the plantar surface $\left(0.125 \mathrm{mg} / \mathrm{cm}^{2}\right)$ of the hind paw of the rats by gentle rubbing with the formulation 50 times with the index finger for each treatment, 1 hour before induction of inflammation. The increase in paw volume (edema) was measured using digital water plethysmometer (PV-01; SINGA Corporation, Taipei, Taiwan) at 0, 1, 2, 3, 4, and 5 hours after carrageenan administration. The percentage of paw thickness increase from time zero was calculated for each group.

\section{Skin-blanching assay}

After shaving the abdominal skin of anesthetized rats, formulations were applied and left on the skin for a period of 1 hour. The degree of blanching was quantified at different time intervals before and after application of the formulations with a Minolta chromameter (CR-400; Konica Minolta, Ramsey, NJ, USA). The instrument was calibrated using the white calibration plate immediately before the study. Baseline readings (zero time) were taken at the untreated control site prior to the application of the formulations. At each observation time, the recorded $L$-, $a$ - and $b$-values for each treated and untreated sites were corrected, by subtracting the baseline (time zero) values to yield baseline corrected values. ${ }^{25}$

\section{TEWL measurement}

TEWL measurement was performed with the anesthetized rats by Tewameter (Courage+Khazaka Electronic GmbH, Cologne, Germany) equipped with a TEWL probe. All measurements were taken before and after application of the formulations for 2 minutes by keeping the probe over rat abdominal skin after the removal of the hair in a certain area of $2 \mathrm{~cm} \times 2 \mathrm{~cm}$. All data were expressed in $\mathrm{g} / \mathrm{m}^{2} \mathrm{~h}$ after measurements of six replicates. ${ }^{26}$

\section{Statistical analysis}

Statistical data analyses were performed on all data using one-way analysis of variance followed by a multiparametric
Tukey's post-hoc test, with $P<0.05$ set as the minimal level of significance.

\section{Results and discussion Preparation and characterization of nanoparticles}

It was previously shown that spherical nanoparticles can be formed by using lecithin and chitosan depending on the electrostatic interaction between the polycationic chitosan and negatively charged soybean lecithin in which lecithin molecules form the core and chitosan molecules form the hydrophilic shell layer to protect the inner structure. ${ }^{17,18}$ Therefore, DFV-loaded homogenous lecithin/chitosan nanoparticles were successfully prepared using direct injection method with small particle size distribution (polydispersity index $<0.2$ ) in this study. As shown in Table 1, nanoparticles with high positive surface charge were attributed to the presence of chitosan chains on the particle surface $(41.4 \pm 1.60 \mathrm{mV})$.

The linearity of the calibration curve for DFV has been established within the concentration range of $0.5-12.5 \mu \mathrm{g} / \mathrm{mL}$, with a correlation coefficient of $\mathrm{R}^{2}=0.9997$. Compared with nanoparticles prepared without IPM, significantly higher entrapment efficiency and DFV loading were obtained with nanoparticles including IPM $(P<0.05)$. The entrapment efficiency and the drug loading of lecithin/chitosan nanoparticles ranged from $53.2 \%$ to $86.8 \%$ and from $6.3 \%$ to $10.3 \%$, respectively. This result was in accordance with previously published data. ${ }^{16}$ It was considered that DFV, due to its lipophilic structure, was located in the lipid core of lecithin/ chitosan nanoparticles whose lipid composition has been modified by the presence of IPM. Thus, IPM existence in nanoparticle formulation enhanced the entrapment efficiency, and as a result, further experiments were performed with the nanoparticle formulations containing IPM (both blank and DFV-loaded nanoparticles).

TEM images of nanoparticles showed spherical particles (Figure 1A), and the particles were characterized (Figure 1B) by a contrasted corona (chitosan) surrounding a lipidic core

Table I Physicochemical properties of nanoparticles

\begin{tabular}{|c|c|c|c|c|}
\hline $\begin{array}{l}\text { Nanoparticle } \\
\text { formulations }\end{array}$ & IPM & $\begin{array}{l}\text { Particle size } \pm \text { SD } \\
(\mathrm{nm})\end{array}$ & $\begin{array}{l}\text { Zeta potential } \pm \text { SD } \\
(\mathrm{mV})\end{array}$ & $\begin{array}{l}\text { Polydispersity } \\
\text { index } \pm \text { SD }\end{array}$ \\
\hline Blank & - & $218.2 \pm 15.1$ & $25.1 \pm 1.80$ & $0.190 \pm 0.05$ \\
\hline DFV loaded & - & $210.7 \pm 10.5$ & $30.4 \pm 2.40$ & $0.152 \pm 0.03$ \\
\hline Blank & $X$ & $210.4 \pm 11.2$ & $38.3 \pm 2.51$ & $0.180 \pm 0.04$ \\
\hline DFV loaded & $x$ & $204.2 \pm 10.1$ & $41.4 \pm 1.60$ & $0.149 \pm 0.02$ \\
\hline
\end{tabular}

Abbreviations: DFV, diflucortolone valerate; IPM, isopropyl myristate; SD, standard deviation. 

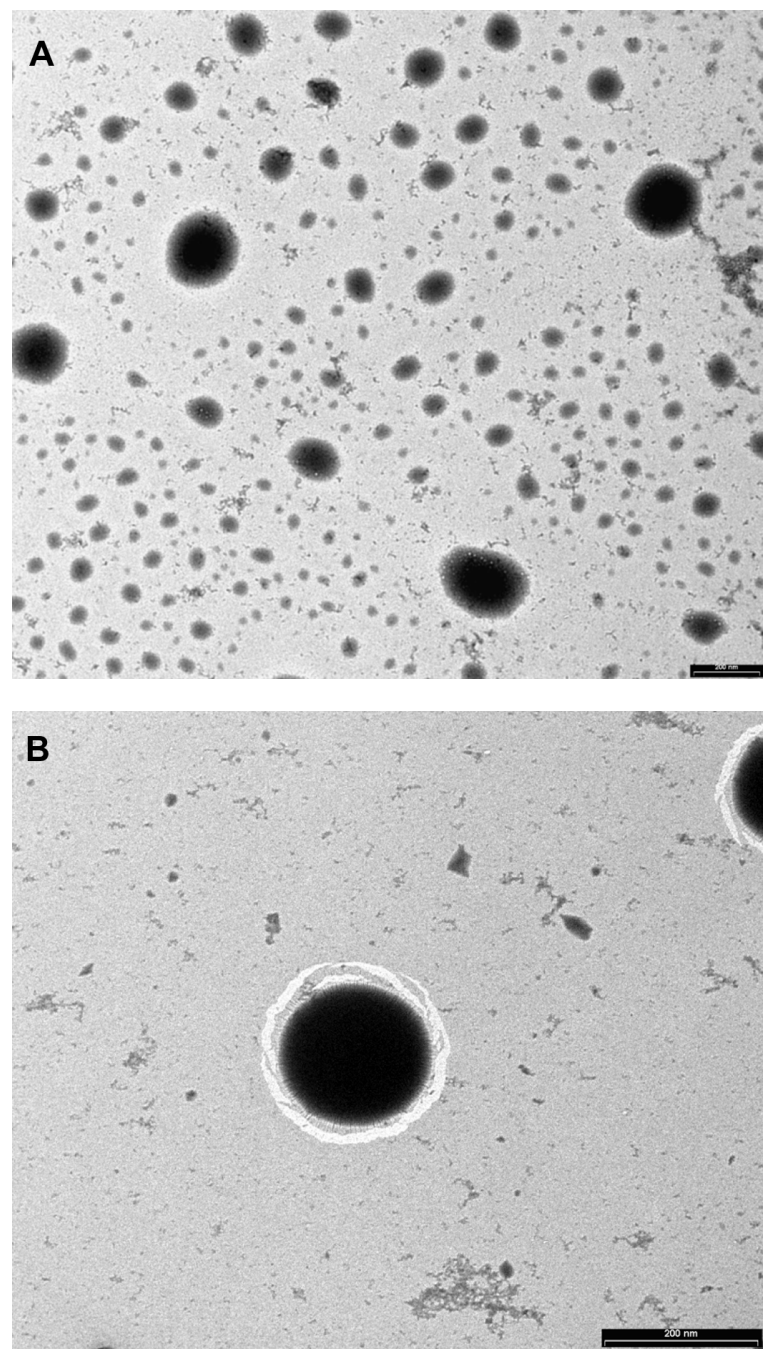

Figure I Transmission electron microscopy images of diflucortolone valerateloaded nanoparticles at magnification ratio of $33,000 \times(\mathbf{A})$, at magnification ratio of $71,000 \times(B)$.

(lecithin+IPM) in which the drug was reasonably dissolved. A good correlation was obtained in the particle size as observed by both zetasizer and TEM.

Furthermore, DSC studies were performed, and DFVloaded nanoparticles showed no melting peak, indicating the absence of crystallinity; whereas DFV in pure form exhibited a melting peak at $207^{\circ} \mathrm{C}$, indicating crystalline nature of the drug (Figure 2). The results of the DSC experiments confirmed the loading of DFV into lecithin/chitosan nanoparticles.

The in-vitro release of DFV from the lecithin/chitosan nanoparticles was investigated using a dialysis bag. ${ }^{27}$ This method has been used to distinguish the differences between formulations that affect the release behavior of DFV. Figure 3 shows the in-vitro release profile of DFV from nanoparticles. A sustained drug release over a period of 24 hours was observed without any initial burst release, confirming the strong interaction between lecithin and chitosan. ${ }^{14}$ DSC analysis also confirmed that DFV was amorphously distributed within the lipidic matrix and did not present on the surface, which might be the probable reason for no initial burst release of drug during in-vitro release experiments. The cumulative release data were fitted into different release models: zero order, first order, Higuchi's square root plot, and Hixson Crowell cube root plot. Zero order release pattern was best fitted with release profile of the formulation with $\mathrm{r}^{2}$ of 0.996 .

Stability studies were performed with prepared nanoparticle dispersions. After 3 months of storage, blank and DFV-loaded nanoparticle suspensions, which were kept in glass-capped vials at $25^{\circ} \mathrm{C}$ and $60 \%$ relative humidity, showed good stability of the colloidal suspension, without evidence of aggregation or precipitation. No significant changes were obtained in the physicochemical characterization parameters $(P>0.05)$ (Table 2).

\section{Preparation and characterization of gels}

To design a more suitable formulation for topical delivery, aqueous chitosan gels were prepared and nanoparticle suspensions were incorporated in these gels at three different ratios (nanoparticle/gel 1:1, 1:3, and 1:9). The most significant property that forms an advantage for these gel formulations is maintaining the formulation duration over the skin for a certain period of time, therefore increasing the efficiency.

The $\mathrm{pH}$ values of all gel formulations were found to be acceptable and similar to skin $\mathrm{pH}$ (average of $4.80 \pm 0.12$ ), as the formulation is intended for topical use. The rheological properties of semisolid vehicles are important as they have the potential to affect the sensory feeling of formulations. ${ }^{28}$ Similarly, these rheological properties are also important, in order to predict the effects of the formulations and improve their quality and stability. Figure 4 shows the rheograms of prepared gel formulations obtained by plotting the applied shear rate as a function of the shear stress. As it can be seen in the rheograms, the formulations showed non-Newtonian behavior in which the viscosity decreases with increasing shear rate. ${ }^{3}$ All formulations exhibited shear-thinning behavior that is a desired property in topical preparations because it facilitates the application on the skin surface. In addition to that, the viscosity values of gels decreased with increasing amount of DFV nanoparticles in formulations, as expected. These results are in accordance with the literature findings. ${ }^{29}$ Similarly, a study by Mucha et $\mathrm{al}^{30}$ reported an increase in the shear stress and viscosity of chitosan solutions with 


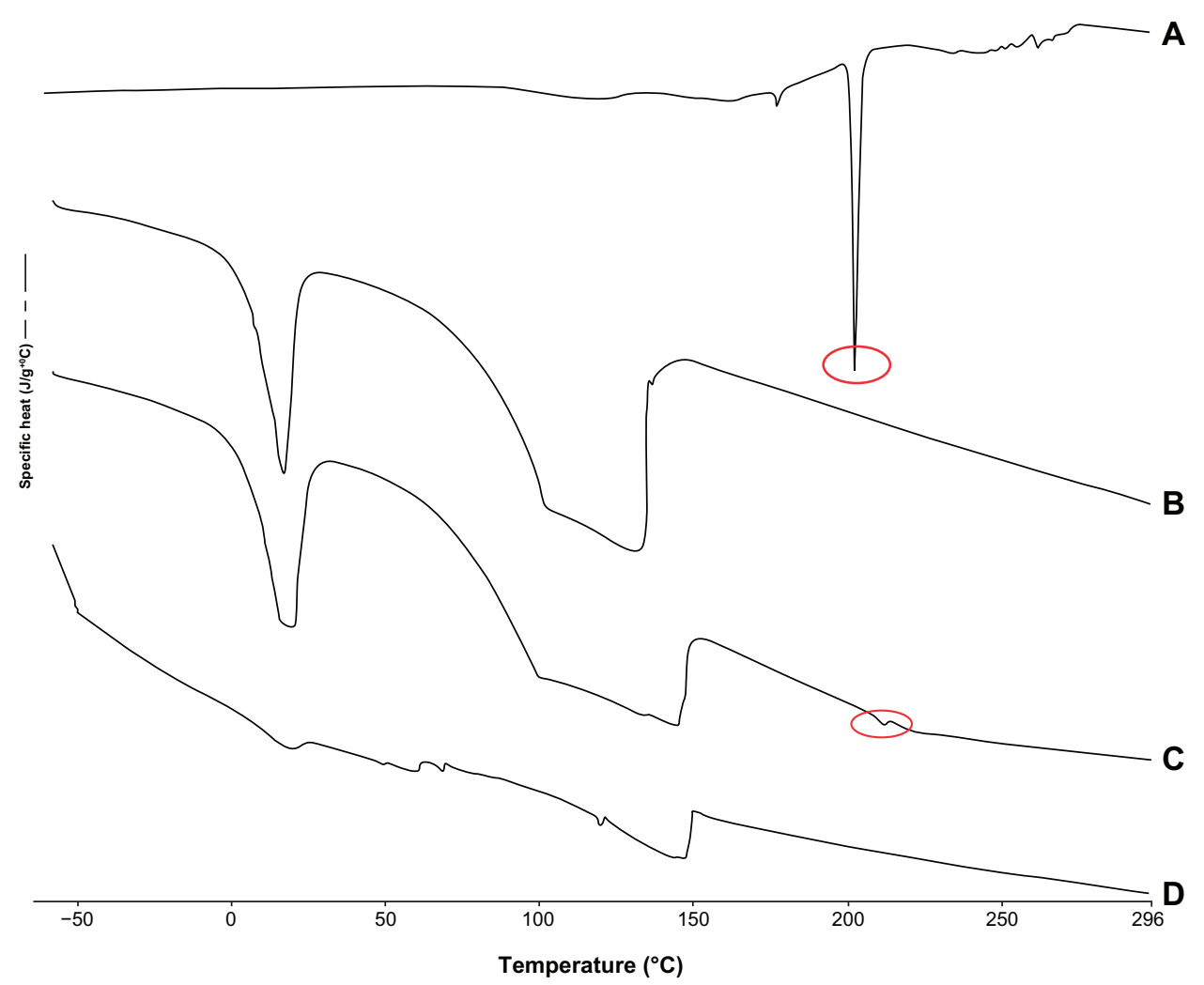

Figure 2 Differential scanning calorimetry thermograms of pure DFV (A), blank nanoparticles (B), physical mixture of blank nanoparticles and DFV (C), and drug-loaded nanoparticles (D).

Abbreviation: DFV, diflucortolone valerate.

increasing chitosan concentration also due to the increase in entanglement among the macromolecular chains.

The possible interaction between a nanocarrier and a vehicle system should possibly affect the viscoelastic properties of the topical formulation. In accordance with that, the movement capability of the nanocarrier in the vehicle should also be influenced by these interactions, if any are present. ${ }^{28}$ Therefore, the change in rheological properties of the gel formulations in response to nanoparticle addition was measured using a constant strain in the linear viscoelastic regions for the formulations. In this study, oscillatory stress sweep test was performed to determine the linear viscoelastic regimen for all formulations. The constant stress was found as $0.06 \mathrm{~Pa}$ for frequency sweep

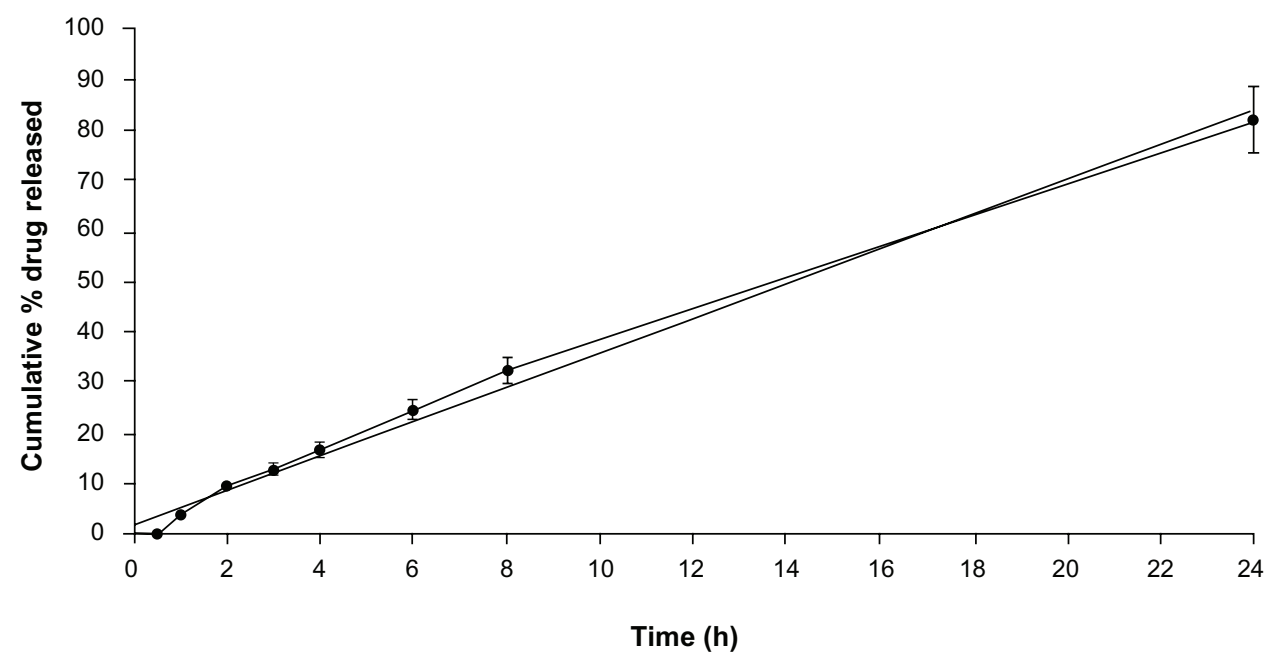

Figure 3 The in-vitro drug-release profile of diflucortolone valerate from nanoparticles $(n=6)$. 
Table 2 Stability results of the nanoparticle formulations

\begin{tabular}{llll}
\hline $\begin{array}{l}\text { Time } \\
\text { (days) }\end{array}$ & $\begin{array}{l}\text { Particle size } \pm \\
\text { SD }(\mathbf{n m})\end{array}$ & $\begin{array}{l}\text { Zeta potential } \pm \\
\text { SD }(\mathbf{m V})\end{array}$ & $\begin{array}{l}\text { Polydispersity } \\
\text { index } \pm \text { SD }\end{array}$ \\
\hline 10 & $213.4 \pm 12.4$ & $35.3 \pm 3.2$ & $0.190 \pm 0.03$ \\
& $206.5 \pm 6.2$ & $40.8 \pm 1.24$ & $0.144 \pm 0.04$ \\
30 & $215.6 \pm 10.5$ & $33.4 \pm 4.5$ & $0.186 \pm 0.06$ \\
& $205.9 \pm 4.8$ & $42.4 \pm 1.69$ & $0.138 \pm 0.01$ \\
60 & $215.9 \pm 8.7$ & $34.2 \pm 2.8$ & $0.192 \pm 0.05$ \\
& $208.2 \pm 8.3$ & $40.8 \pm 2.01$ & $0.156 \pm 0.03$ \\
90 & $216.5 \pm 10.6$ & $32.6 \pm 3.5$ & $0.191 \pm 0.08$ \\
& $208.5 \pm 10.4$ & $42.2 \pm 1.77$ & $0.154 \pm 0.04$ \\
\hline
\end{tabular}

Note: Grey line for blank nanoparticles.

Abbreviation: SD, standard deviation.

analysis, which was performed to determine the viscoelastic performance of formulations. The storage (elastic) modulus $\left(\mathrm{G}^{\prime}\right)$ and loss (viscous) modulus $\left(\mathrm{G}^{\prime}\right)$ were measured for gel formulations. ${ }^{31,32}$ The storage modulus as a function of frequency for chitosan hydrogels of varying nanoparticle concentrations are presented in Figure 5. Altering the concentration of nanoparticles dramatically changed the viscoelastic properties of the gel. Reduction of the percentage of nanoparticle in the gel from $50 \%$ to $10 \%$ increased the $\mathrm{G}^{\prime}$ values. The enhancement of the elastic modulus with the chitosan concentration has been attributed to the presence of more polymer chains responsible for more entangled junctions. ${ }^{28}$

Mechanical properties of gels for topical delivery are important for the maximum benefit of the patient from the formulation; these being responsible for the correct dosage transfer to the target site and easy application on the substrate. Texture profile analysis defines the mechanical parameters in terms of hardness, adhesiveness, cohesiveness, compressibility, and elasticity. The mechanical properties of formulations are shown in Table 3. The hardness and compressibility of the gels were raised when the viscosity of the gel formulations increased. The highest compressibility $(0.028 \pm 0.004 \mathrm{~N} \cdot \mathrm{mm})$ was obtained with 1:9 ratio. All gel formulations showed high cohesiveness $(>0.857 \mathrm{~N} \cdot \mathrm{mm})$, and they also had an acceptable elasticity value compared with previous literature findings. ${ }^{33}$ In this study, the adhesiveness of gel decrement was affected by added nanoparticle ratio. All the formulations were found easily spreadable and nondripping in nature.

The stability of chitosan gels containing lecithin/chitosan nanoparticles in terms of drug content and gel stability was investigated during 3 months. No significant change was observed for the $\mathrm{pH}$, viscosity, and drug content values of the formulations $(P>0.05)$. No phase separation was detected, which indicated that chitosan gel containing DFV nanoparticles had good physical stability.

\section{Skin permeation experiments}

It is well known that vehicles used in topical formulations can greatly influence the rate and extent of drug permeation into and across the skin, which clearly modifies the potency of the topical corticosteroid formulation. The nanoparticles tended to suppress the penetration (transdermal delivery) through the skin while enhancing permeation (dermal delivery) of the drug into the upper skin layers. For this purpose, in order to assess the advantages of this carrier-based formulation in topical administration, the accumulation and permeation across rat skin were compared with chitosan gel and commercially available cream of DFV.

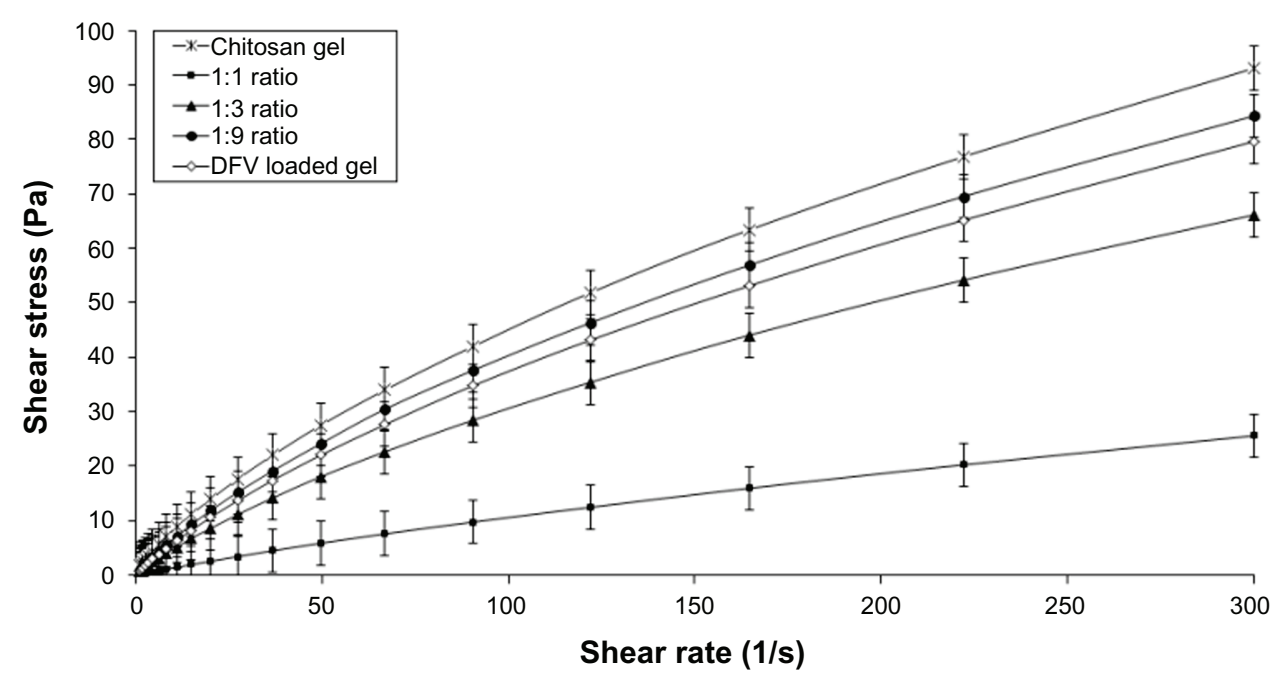

Figure 4 Flow rheograms of chitosan gel formulations - shear rate versus shear stress $(n=3)$. Abbreviations: DFV, diflucortolone valerate; $\mathrm{Pa}$, pascal. 


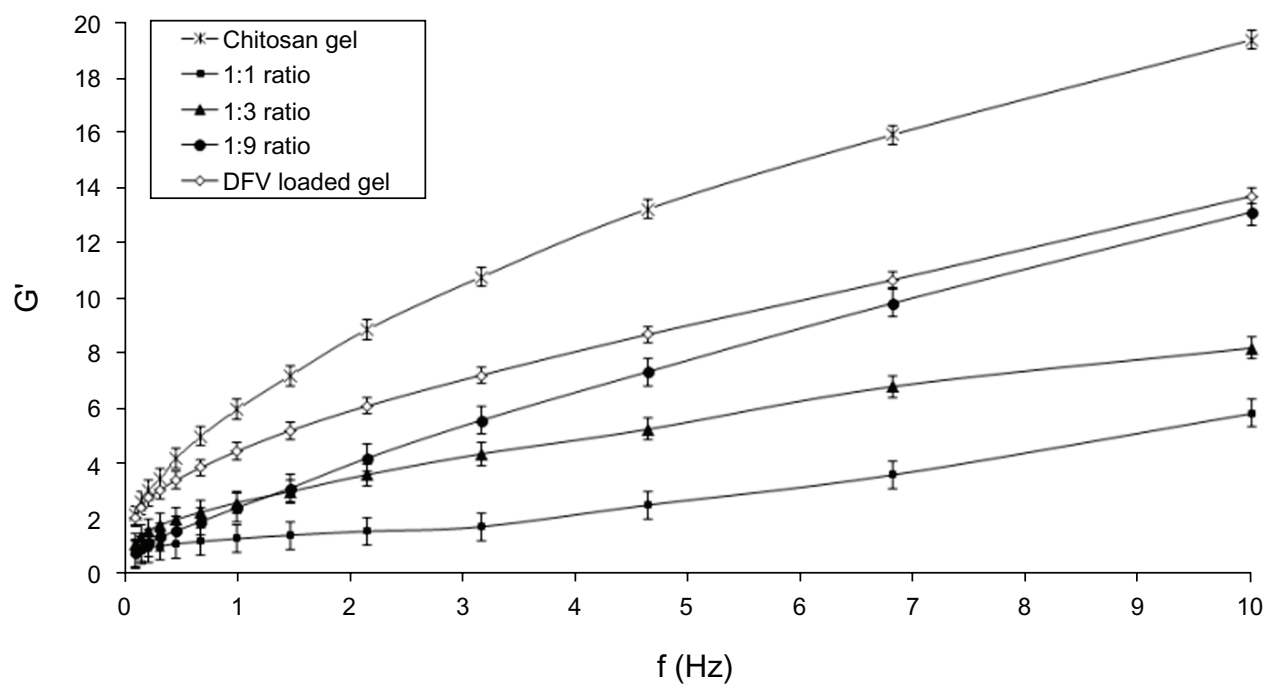

Figure 5 The elastic modulus plotted versus frequency of formulations $(n=3)$. Abbreviation: DFV, diflucortolone valerate; $\mathrm{G}^{\prime}$, elastic (storage) modulus.

In the permeation experiments, two parameters were obtained: (1) the rate of permeation (flux) of the drug through the skin into the receptor fluid; and (2) the concentration of the drug in the skin (SC+epidermis and dermis). ${ }^{34}$ Permeation rates were calculated by taking samples from the receptor phase at various time points, while the skin concentration reported here refers to the 6-hour time point at the end of the experiment.

During the permeation studies, DFV was not found in the receptor medium with any preparation at the end of 6 hours. This indicated that the activity of the drug presented in the skin did not produce a significant transdermal transport through the rat skin throughout the experiment. Therefore, the drug accumulated in the skin sample layers was investigated. The amounts of DFV accumulated in the skin layers was normalized by the weight of tissue and expressed as $\mu \mathrm{g}$ DFV per mg of tissue. Figure 6 presents the amount of DFV found in the $\mathrm{SC}+$ epidermis and dermis.

The direct application of the nanoparticle colloidal suspension on skin surface was performed to show the vehicle effect.
It produced a significantly higher amount of DFV in the $\mathrm{SC}+$ epidermis and dermis in comparison with the tested dosage forms $(P<0.05)$. The enhancement ratio of the nanoparticle dispersion versus commercial cream was calculated to demonstrate the accumulating capacity of lecithin/chitosan nanoparticles. The results indicated that these nanoparticles showed 6.33- and 5.79-fold higher retention compared with commercial cream for DFV in SC+epidermis and dermis, respectively. The statistical difference between the nanoparticle dispersion and the semisolid formulation group in the accumulation of DFV in the SC+epidermis could be due to the unique characteristics of the prepared nanoparticles, as well as their positive charge and large surface area, ensuring an excellent contact surface between the vehicles and skin over the entire application area and promoting permeation and accumulation of drug in the skin. ${ }^{18}$

Since epidermal lipids are found in high amounts within the penetration barrier, lipid carriers attach themselves to the skin surface and allow lipid exchange between the outer-

Table 3 Mechanical properties of formulations

\begin{tabular}{|c|c|c|c|c|c|c|}
\hline Formulation & Ratio & $\begin{array}{l}\text { Hardness } \\
\text { (N) } \pm \text { SD }\end{array}$ & $\begin{array}{l}\text { Compressibility } \\
(\mathbf{N} \cdot \mathbf{m m}) \pm \mathbf{S D}\end{array}$ & $\begin{array}{l}\text { Adhesiveness } \\
(\mathbf{N} \cdot \mathbf{m m}) \pm \mathbf{S D}\end{array}$ & $\begin{array}{l}\text { Cohesiveness } \\
\pm \text { SD }\end{array}$ & $\begin{array}{l}\text { Elasticity } \\
\pm \text { SD }\end{array}$ \\
\hline Chitosan gel & & $0.012 \pm 0.001$ & $0.026 \pm 0.004$ & $0.018 \pm 0.001$ & $0.926 \pm 0.052$ & $0.814 \pm 0.078$ \\
\hline DFV-loaded chitosan gel & & $0.012 \pm 0.002$ & $0.027 \pm 0.003$ & $0.016 \pm 0.002$ & $0.899 \pm 0.046$ & $0.845 \pm 0.075$ \\
\hline Blank nanoparticle/ & $\mathrm{I}: \mathrm{I}$ & $0.008 \pm 0.002$ & $0.019 \pm 0.001$ & $0.009 \pm 0.001$ & $0.898 \pm 0.013$ & $0.813 \pm 0.059$ \\
\hline \multirow[t]{2}{*}{ chitosan gel } & $\mathrm{I}: 3$ & $0.009 \pm 0.001$ & $0.021 \pm 0.001$ & $0.011 \pm 0.001$ & $0.925 \pm 0.011$ & $0.957 \pm 0.087$ \\
\hline & $\mathrm{I}: 9$ & $0.009 \pm 0.002$ & $0.022 \pm 0.004$ & $0.016 \pm 0.001$ & $0.943 \pm 0.043$ & $0.927 \pm 0.063$ \\
\hline DFV-loaded nanoparticle/ & $\mathrm{I}: \mathrm{I}$ & $0.009 \pm 0.001$ & $0.021 \pm 0.002$ & $0.010 \pm 0.002$ & $0.910 \pm 0.014$ & $0.962 \pm 0.052$ \\
\hline \multirow[t]{2}{*}{ chitosan gel } & $1: 3$ & $0.010 \pm 0.001$ & $0.023 \pm 0.003$ & $0.012 \pm 0.002$ & $0.857 \pm 0.021$ & $0.916 \pm 0.028$ \\
\hline & $1: 9$ & $0.012 \pm 0.001$ & $0.028 \pm 0.004$ & $0.016 \pm 0.001$ & $0.894 \pm 0.042$ & $0.882 \pm 0.039$ \\
\hline
\end{tabular}

Abbreviations: DFV, diflucortolone valerate; SD, standard deviation. 


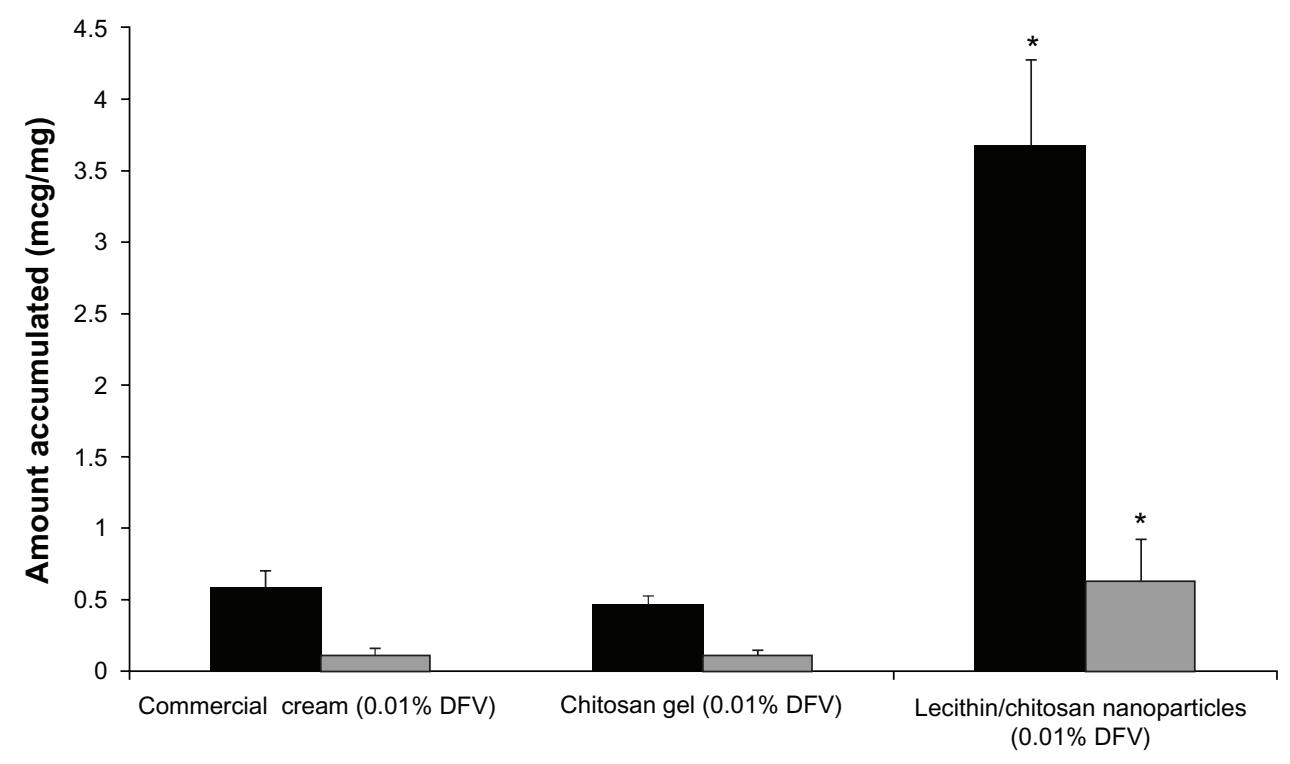

Figure 6 Amount of DFV accumulated from formulations in the SC+epidermis (dark bars) and dermis (light bars) $(n=6)$.

Note: *Denotes significantly different from commercial cream and chitosan gel $(P<0.05)$.

Abbreviations: DFV, diflucortolone valerate; SC, stratum corneum.

most layers of the skin and enhance the penetration of active substances. As expected, the penetration enhancer effect of lecithin/chitosan nanoparticles was determined both in $\mathrm{SC}+$ epidermis and dermis. Overall, it can be concluded that lecithin, the main component of our system, was responsible for the enhancer effect.

Moreover, the accumulation studies of DFV from nanoparticle colloidal suspension incorporated in chitosan gels at different ratios $(1: 9,1: 3$, and 1:1, DFV concentrations of $0.01 \%, 0.025 \%$, and $0.05 \% \mathrm{w} / \mathrm{w}$, respectively) were realized. The presence of nanoparticles in chitosan gels produced lower skin retention of DFV compared with the undiluted form of nanoparticles. The result disclosed that the increased amount of nanoparticles in chitosan gel did not significantly affect the skin retention of DFV $(P>0.05)$ (Figure 7). Therefore, it can be assumed that the concentration of nanoparticles in chitosan gels does not seem to play a determinant role.

It was found that gel formulation prepared at 1:9 ratio increased the retention of DFV in the skin layers when compared with commercial cream. It is a remarkable point to consider that although the concentration of DFV was 10 times higher in the commercial cream formulation with

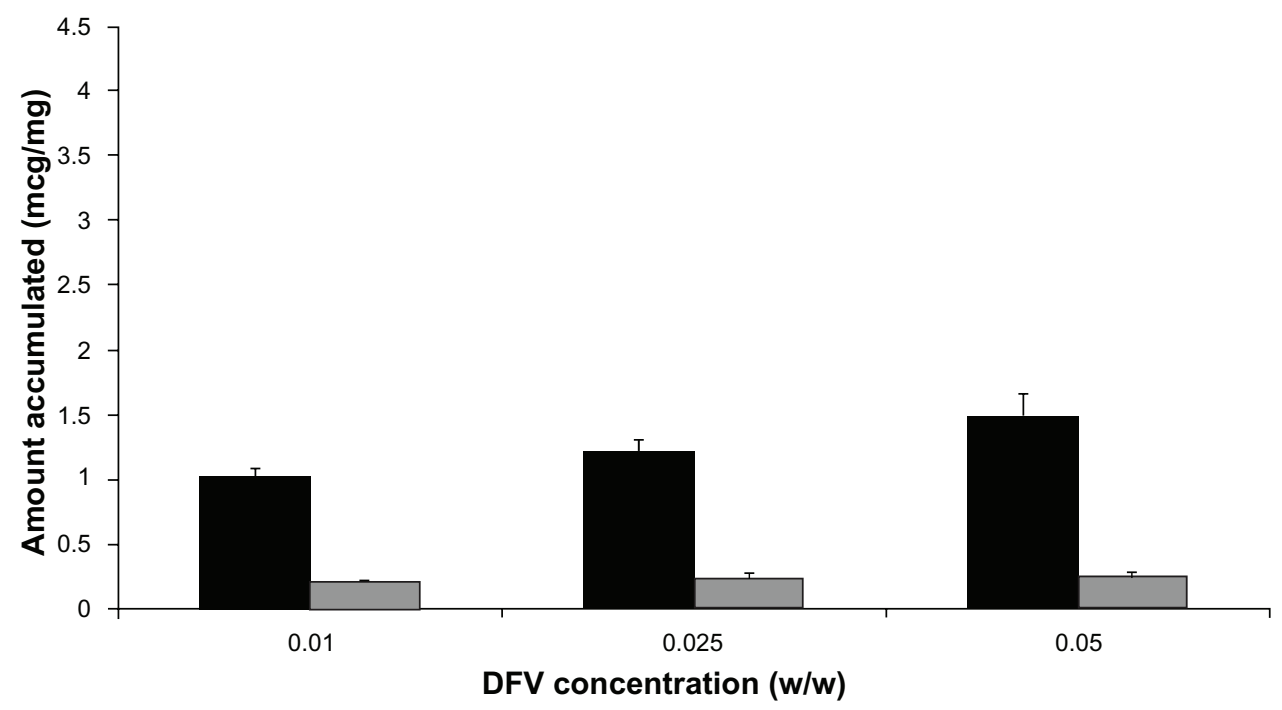

Figure 7 Accumulation of DFV from nanoparticles in chitosan gels as a function of drug concentration in the SC+epidermis (dark bars) and dermis (light bars) ( $\mathrm{n}=6$ ). Abbreviations: DFV, diflucortolone valerate; SC, stratum corneum. 
respect to the gel; the retention of DFV in the skin layers was significantly higher with gel formulations $(P<0.05)$.

\section{In-vivo studies}

\section{Anti-inflammatory activity studies}

The anti-inflammatory activity of the formulations was evaluated by hind-paw edema test using plethysmometer, which is the most convenient, rapid, and accurate assessment technique, providing the measurement of changes in paw volume by water displacement. ${ }^{24}$ In this study, the progress of the paw edema test was in accordance with the previous findings existing in the literature. ${ }^{35}$ Induction of acute inflammation in control rats resulted in a prominent increase in paw thickness throughout the first hour after intraplantar injection of carrageenan and reached a peak of inflammation after 3 hours (Figure 8). From the statistical analysis, it was found that gel formulations containing DFV nanoparticles had a significant anti-inflammatory effect $(P<0.05)$ compared with commercial and control groups. Overall, according to these results, nanoparticle in gel (1:9) formulation can be considered promising topical formulations with better anti-inflammatory activity than commercial cream for effective therapy.

\section{Skin blanching assay}

In the specific case of steroids, the skin blanching (or vasoconstriction) response is a useful technique, which provides information on potency of the drug or efficacy of the delivery vehicle. The assay is also useful for the comparison of the topical availability of corticosteroid formulations containing the same concentration of the same corticosteroid. ${ }^{22,36}$ In many studies, the vasoconstriction assay employed visual evaluation of the degree of blanching by trained observers. ${ }^{37,38}$

In this study, a chromameter was utilized to quantify and compare the vasoconstrictor effect of DFV. Chromameters are compact portable instruments used for the assessment of surface color based on the tristimulus analysis of a reflected xenon light pulse. The major advantage of this device is to minimize the relativity factor depending on the human eye. ${ }^{39}$ Moreover, this method is noninvasive and involves only one investigator, instead of several trained judges for visual scoring. In principle, the chromameter records threedimensional color reflectance including " $L$ ", " $a$ " and " $b$ ". $L$ represents luminance, which is the relative brightness value, with 0 meaning totally black and 100 meaning pure white. The balance between red (100)/green $(-100)$ and yellow $(100)$ /blue $(-100)$ is represented by " $a$ " and " $b$ ", respectively. ${ }^{40}$ Blanching effect that expected to be formed after administration of formulation on male albino Wistar rat skin was measured with the chromameter, and the results were correlated to the results of ex-vivo permeation studies. The difference in color $(\Delta a)$ between the gel-treated site and the untreated site as the control were described.

Studies on corticosteroids indicated that drug content in the SC+epidermis could be related to the skin-blanching response and that drug concentration may be used to estimate formulation efficiency. SC drug concentration could be affected by different factors, among which application

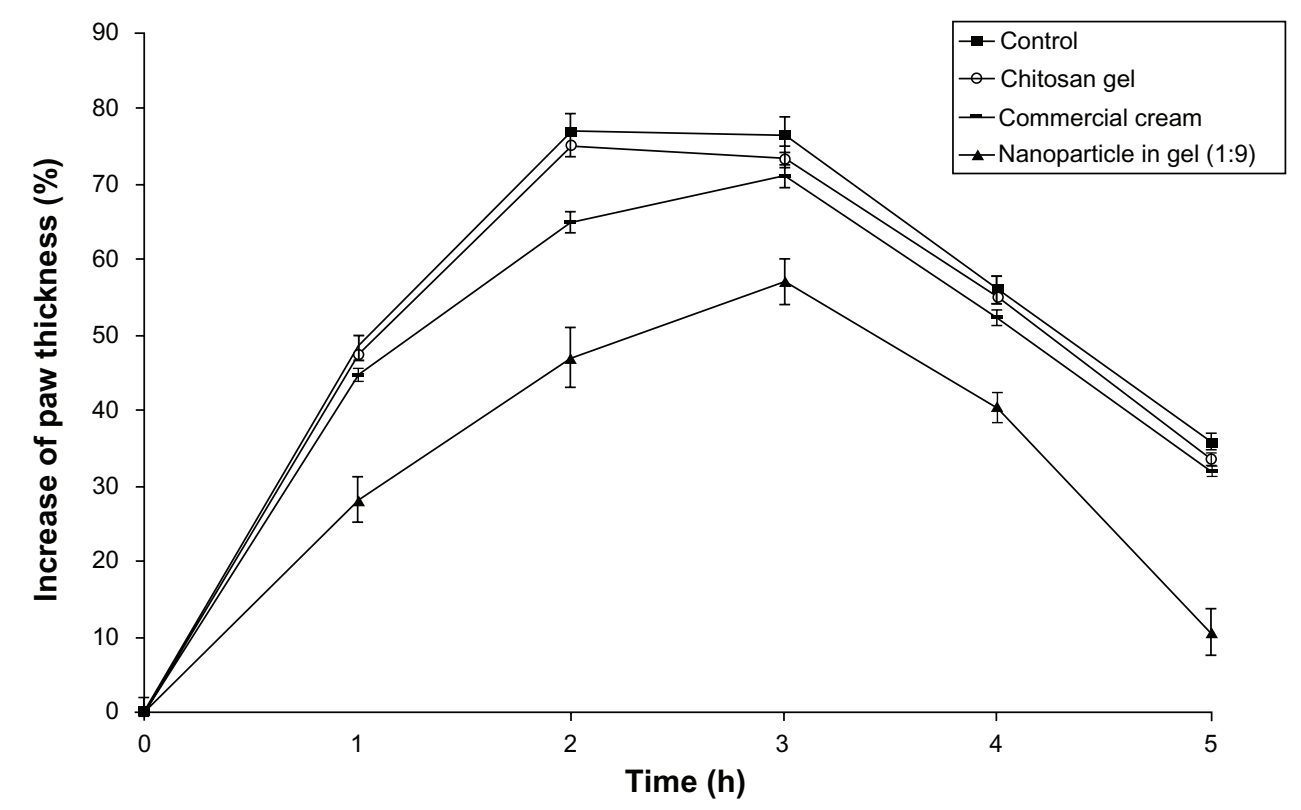

Figure 8 Changes in the paw thickness of the rats with respect to time after formulation application $(n=6)$. 
conditions (application time, vehicle composition, drug concentration in the vehicle, anatomical site) may play an important role. ${ }^{41}$ Therefore, drug content in the SC+epidermis was determined and correlated with the observed skin blanching effect.

Various studies, using a vasoconstrictor assay, have shown that huge differences exist between generic and original formulations containing the same glucocorticoid at the same concentration in different vehicles. ${ }^{42}$ The amount of drug needed for the same blanching response differs according to the steroid solubility in the vehicle. However, the same thermodynamic activity of the drug in the vehicle leads to the same pharmacodynamic response, provided that the formulation does not change either the solubility of the drug in the SC or its diffusivity across the SC. In one study, the skin blanching response of betamethasone 17-benzoate increases proportionally with the concentration of the dissolved and diffusible drug, reaching the maximal response when the concentration equals the solubility of the drug in the vehicle. The blanching response from suspensions of the drug is independent of the betamethasone 17-benzoate concentration. $^{43}$

Montenegro et $\mathrm{al}^{41}$ assessed the effect of application time on skin blanching response and SC concentration after topical application of $0.1 \%$ betamethasone-17-valerate cream. Their study suggested that the duration of application should be carefully chosen to assess drug topical bioavailability, since after long application times, skin blanching response may not be related to drug concentration in the SC. SchaferKorting et $\mathrm{al}^{9}$ suggested that drug levels in the skin layers are reported to parallel dermal availability and to be related to the skin-blanching response of topical glucocorticoids.
Their comparative studies indicated a correlation of in-vitro penetration and in-vivo skin blanching data. In this present study, it was known that lecithin/chitosan nanoparticles dramatically increased the skin accumulation of DFV; skin blanching results were found in accordance with these skin permeation studies. As shown in Figure 9, when compared with the value of color difference $(\Delta a)$ between the control and DFV including formulations of treated site, skin blanching effect was observed. There was no significant difference between the chitosan gel and control group, as was expected $(P>0.05)$. Commercial formulation showed the maximum vasoconstrictor effect at the initial time points ( 2 and 4 hours); but in the last three measurement time points there was no significant difference with the gel formulations containing DFV-loaded nanoparticles $(P>0.05)$. This possibly depends on the fast penetration of DFV from commercial formulations towards the vascular endothelium structure. However, within the time course, the DFV from gel formulations showed similar vasoconstriction activity even though they contain $1 / 10$ of DFV with respect to commercial formulation. The maximum blanching response was obtained at 16 hours after application of the formulations, similar to previously reported corticosteroid skin blanching studies. ${ }^{37,41}$ The similar results between tested gel formulations and commercially available formulation suggest that these gel formulations could also be a good candidate for topical application since they show no penetration..$^{25}$

\section{TEWL measurements}

TEWL measurements, a noninvasive technique commonly used to assess the barrier function of the SC, were also performed. ${ }^{26}$ Prolonged glucocorticosteroid therapy increases

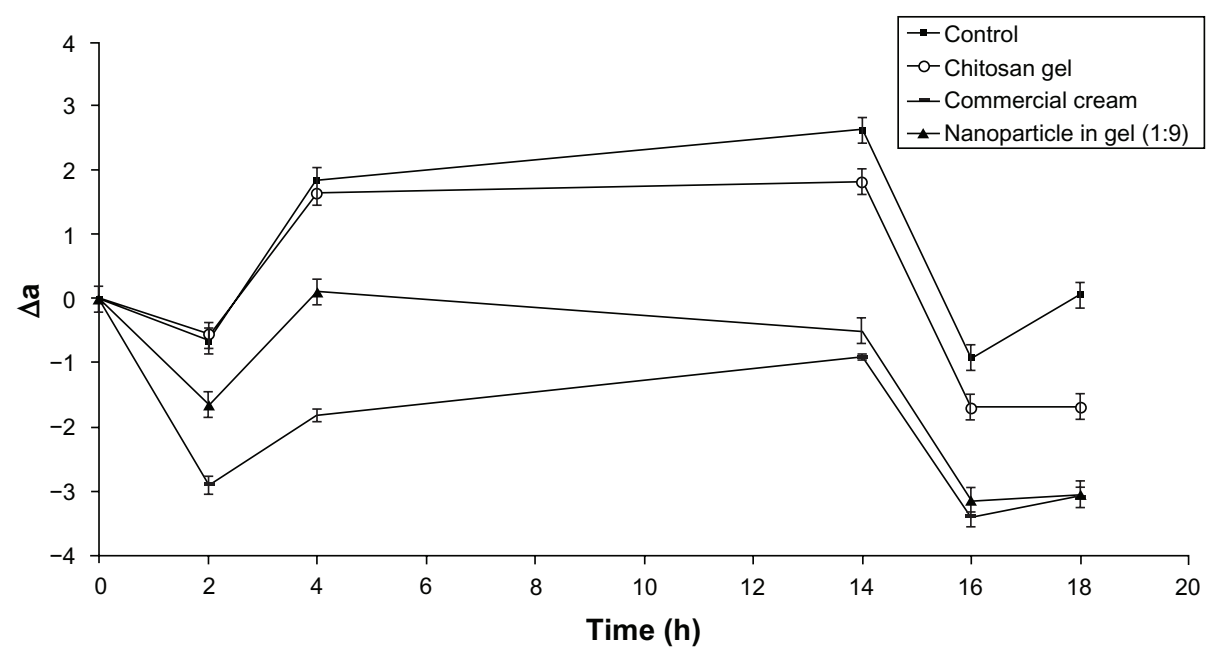

Figure 9 Skin blanching profiles of formulations - the value of color difference $(\Delta a)$ in rats versus time $(n=6)$. 


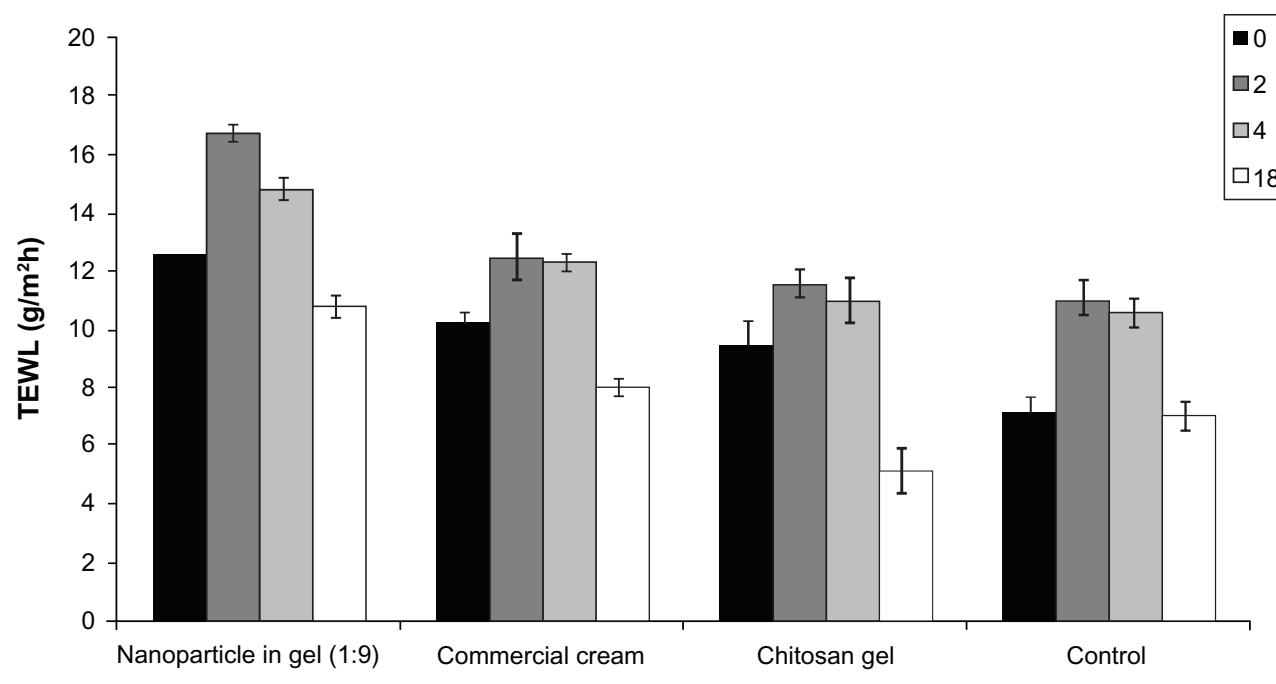

Figure 10 Changes in TEWL values of the rats with respect to time after formulation application $(n=6)$.

Abbreviation: TEWL, transepidermal water loss.

basal TEWL, indicating an effect on permeability barrier function. This change is commonly associated with the reduction of lipid content, SC thickness, and number of lamellar bodies. ${ }^{43,44}$ In this study, after TEWL measurements showed that there was no significant difference $(P>0.05)$ from $12.53 \pm 0.68 \mathrm{~g} / \mathrm{h} \cdot \mathrm{m}^{2}$ to $10.76 \pm 0.45 \mathrm{~g} / \mathrm{h} \cdot \mathrm{m}^{2}$ before and after treatment with nanoparticle in gel, which further suggested that barrier function of the skin (see Figure 10).

\section{Conclusion}

Topical steroid delivery without significant permeation is a challenging issue in treatment of skin disorders. In this study, by formulating lecithin/chitosan nanoparticles, sustained release of DFV was achieved up to 24 hours. In addition, improved accumulation of the DFV in SC+epidermis was successfully accomplished even incorporating these nanoparticles into chitosan gel formulation, which provided a more suitable dosage form for topical drug delivery. Stable chitosan gels containing these DFV-loaded nanoparticles (1:9) showed adequate drug content, compatible $\mathrm{pH}$ with skin, and sufficient rheological and mechanical properties for topical application. Although the amount of DFV in commercial cream formulation was 10 times higher than the gel including nanoparticles, better results were obtained with nanoparticle in gel formulation by means of ex-vivo permeation and in-vivo studies. This is a remarkable point for the reduction of the side effects of DFV. The formulation produced significantly higher anti-inflammatory effect when compared with commercial cream as a result of pharmacodynamic studies in rats $(P<0.05)$. Furthermore, change of skin blanching as a result of vasoconstrictor effect of this formulation, which had no penetration rates, was similar to the commercial product. The system also did not cause any changes in the barrier function of the skin, as confirmed by TEWL measurements. This clearly indicates that chitosan gel, which includes lecithin/chitosan nanoparticles, could be classified as a promising vehicle for the dermal delivery of DFV in various skin disorders.

The formed eczema intensity will be evaluated by both scoring methods and histopathologically for further studies.

\section{Acknowledgments}

This work was supported by The Scientific and Technological Research Council of Turkey (Project number: 109S433).

\section{Disclosure}

The authors report no conflicts of interest in this work.

\section{References}

1. Brazzini B, Pimpinelli N. New and established topical corticosteroids in dermatology: clinical pharmacology and therapeutic use. Am J Clin Dermatol. 2002;3(1):47-58.

2. Patel HK, Barot BS, Parejiya PB, Shelat PK, Shukla A. Topical delivery of clobetasol propionate loaded microemulsion based gel for effective treatment of vitiligo: ex vivo permeation and skin irritation studies. Colloids Surf B Biointerfaces. 2013;102:86-94.

3. Fontana MC, Rezer JF, Coradini K, Leal DB, Beck RC. Improved efficacy in the treatment of contact dermatitis in rats by a dermatological nanomedicine containing clobetasol propionate. Eur J Pharm Biopharm. 2011;79(2):241-249.

4. Fang JY, Wu PC, Huang YB, Tsai YH. In vitro permeation study of capsaicin and its synthetic derivatives from ointment bases using various skin types. Int J Pharm. 1995;126:119-128.

5. Senyigit T, Padula C, Ozer O, Santi P. Different approaches for improving skin accumulation of topical corticosteroids. Int J Pharm. 2009;380:155-160. 
6. Fisher DA. Adverse effects of topical corticosteroid use. West J Med. 1995;162(2):123-126.

7. Levin C, Maibach HI. Topical corticosteroid-induced adrenocortical insufficiency: clinical implications. Am J Clin Dermatol. 2002;3(3): 141-147.

8. Gillet A, Compere P, Lecomte F, et al. Liposome surface charge influence on skin penetration behaviour. Int J Pharm. 2011;411(1-2): $223-231$.

9. Schafer-Korting M, Mehnert W, Korting HC. Lipid nanoparticles for improved topical application of drugs for skin diseases. Adv Drug Deliv Rev. 2007;59:427-443.

10. Senyigit T, Ozcan I, Ozer O. Innovative topical formulations for treatment of dermatitis. Recent Pat Inflamm Allergy Drug Discov. 2012;6(3): 186-201.

11. Gokce EH, Korkmaz E, Dellera E, Sandri G, Bonferoni MC, Ozer O. Resveratrol-loaded solid lipid nanoparticles versus nanostructured lipid carriers: evaluation of antioxidant potential for dermal applications. Int J Nanomedicine. 2012;7:1841-1850.

12. Prow TW, Grice JE, Lin LL, et al. Nanoparticles and microparticles for skin drug delivery. Adv Drug Deliv Rev. 2011;63:470-491.

13. Rajan R, Vasudevan DT. Effect of permeation enhancers on the penetration mechanism of transfersomal gel of ketoconazole. JAdv Pharm Technol Res. 2012;3(2):112-116.

14. Hafner A, Lovrić J, Pepić I, Filipović-Grčić J. Lecithin/chitosan nanoparticles for transdermal delivery of melatonin. J Microencapsul. 2011;28(8):807-815.

15. Ozcan I, Senyigit T, Gökce EH, Ozer O. Current status of chitosan on dermal/transdermal drug delivery systems. In: Davis SP, editor. Chitosan: Manufacture, Properties and Usage. New York: NOVA Science Publishers, Inc; 2010:449-484.

16. Senyigit T, Sonvico F, Barbieri S, Ozer O, Santi P, Colombo P. Lecithin-chitosan nanoparticles of clobetasol-17-propionate capable of accumulation in pig skin. J Control Release. 2010;142(3):368-373.

17. Sonvico F, Cagnani A, Rossi A, et al. Formation of self-organized nanoparticles by lecithin/chitosan ionic interaction. Int J Pharm. 2006; 324:67-73.

18. Tan Q, Liu W, Guo C, Zhai G. Preparation and evaluation of quercetinloaded lecithin-chitosan nanoparticles for topical delivery. Int $J$ Nanomedicine. 2011;6:1621-1630.

19. Horn EJ, Domm S, Katz HI, Lebwohl M, Mrowietz U, Kragballe K. Topical corticosteroids in psoriasis: strategies for improving safety. J Eur Acad Dermatol Venereol. 2010;24(2):119-124.

20. Coleman GL, Kanfer I, Haigh JM. Comparative blanching activities of proprietary, diflucortolone valerate topical preparations. Dermatologica. 1978;156(4):224-230.

21. Haigh JM, Kanfer I. Assessment of topical corticosteroid preparations: the human skin blanching assay. Int J Pharm. 1984;19:245-262.

22. Schwarb FP, Smith EW, Haigh JM, Surber C. Analysis of chromameter results obtained from corticosteroid-induced skin blanching assay: comparison of visual and chromameter data. Eur J Pharm Biopharm. 1999;47:261-267.

23. Jones DS, Lawlor MS, Woolfson AD. Examination of the flow rheological and textural properties of polymer gels composed of poly(methylvinylether-comaleic anhydride) and poly(vinylpyrrolidone): rheological and mathematical interpretation of textural parameters. J Pharm Sci. 2002;91(9):2090-2101.

24. Morris CJ. Carrageenan-induced paw edema in the rat and mouse from: methods in molecular biology. In: Winyard PG, Willoughby DA, editors. Inflammation Protocols. Totowa: Humana Press Inc; 2003: $115-121$.

25. Wu PC, Chang JS, Huang YB, Chai CY, Tsai YH. Evaluation of percutaneous absorption and skin irritation of ketoprofen through rat skin: in vitro and in vivo study. Int J Pharm. 2001;222:225-235.
26. Barel AO, Clarys P. Study of the stratum corneum barrier function by transepidermal water woss measurements: comparison between two commercial instruments: Evaporimeter ${ }^{\circledR}$ and Tewameter ${ }^{\circledR}$. Skin Pharmacol. 1995;8(4):186-195.

27. Jain S, Mittal A, Amit JK. Enhanced topical delivery of cyclosporine-A using PLGA nanoparticles as carrier. Curr Nanosci. 2011;7(4): 524-530.

28. Moddaresi M, Brown MB, Zhao Y, Tamburic S, Jones SA. The role of vehicle-nanoparticle interactions in topical drug delivery. Int J Pharm. 2010;400:176-182.

29. El-Hefian EA, Yahaya AH. Rheological study of chitosan and its blends: an overview. Maejo Int J Sci Technol. 2010;4(2):210-220.

30. Mucha M. Rheological characteristics of semi-dilute chitosan solutions. Macromol Chem Phys. 1997;198:471-484.

31. Hernández R, Zamora-Mora V, Sibaja-Ballestero M, Vega-Baudrit J, López D, Mijangos C. Influence of iron oxide nanoparticles on the rheological properties of hybrid chitosan ferrogels. J Colloid Interface Sci. 2009;339:53-59.

32. José Moura M, Margarida Figueiredo M, Helena Gil M. Rheological study of genipin cross-linked chitosan hydrogels. Biomacromolecules. 2007;8:3823-3829.

33. Jones DS, Woolfson AD, Brown AF. Textural, viscoelastic and mucoadhesive properties of pharmaceutical gels composed of cellulose polymers. Int J Pharm. 1997;151:223-233.

34. Billich A, Aschauer H, Aszódi A, Stuetz A. Percutaneous absorption of drugs used in atopic eczema: pimecrolimus permeates less through skin than corticosteroids and tacrolimus. Int J Pharm. 2004;269:29-35.

35. Senyigit T, Tekmen I, Sonmez U, Santi P, Ozer O. Deoxycholate hydrogels of betamethasone-17-valerate intended for topical use: in vitro and in vivo evaluation. Int J Pharm. 2011;403:123-129.

36. Mugglestone CJ, Mariz S, Lane ME. The development and registration of topical pharmaceuticals. Int J Pharm. 2012;435:22-26.

37. Bach M, Lippold BC. Influence of penetration enhancers on the blanching intensity of betamethasone 17-benzoate. Int J Pharm. 1998;168: 97-108.

38. Herkenne C, Alberti I, Naik A, et al. In vivo methods for the assessment of topical drug bioavailability. Pharm Res. 2008;25(1):87-103.

39. Haigh JM, Meyer E, Smith EW, Kanfer I. The human skin blanching assay for in vivo topical corticosteroid assessment II. Subject- and observer-dependent variation in blanching responses. Int J Pharm. 1997;152:185-192.

40. Pershing LK, Bakhtian S, Poncelet G, Corlett JL, Shah VP. Comparison of skin stripping, in vitro release, and skin blanching response methods to measure dose response and similarity of triamcinolone acetonide cream strengths from two manufactured sources. J Pharm Sci. 2002;91: 1312-1323.

41. Montenegro L, Ademola JI, Bonina FP, Maibach HI. Effect of application time of betamethasone-17-valerate $0.1 \%$ cream on skin blanching and stratum corneum drug concentration. Int J Pharm. 1996;140: $51-60$.

42. Woodford R, Barry BW. Bioavailability and activity of betamethasone 17-benzoate in gel and cream formulations: comparison with proprietary topical corticosteroid preparations in the vasoconstrictor assay. Curr Ther Res. 1974;16(4):338-345.

43. Lamaud L, Lambrey B, Schalla W, Schaefer H. Correlation between transepidermal water loss and penetration of drugs. J Invest Dermatol. 1984;82:556-563.

44. Wester RC, Maibach HI. Human percutaneous absorption and transepidermal water loss (TEWL) correlation. In: Bronaugh RL, Maibach HI, editors. Percutaneous Absorption. Florida: Taylor and Francis, Boca Raton; 2005:509-520. 
International Journal of Nanomedicine

Dovepress

\section{Publish your work in this journal}

The International Journal of Nanomedicine is an international, peerreviewed journal focusing on the application of nanotechnology in diagnostics, therapeutics, and drug delivery systems throughou the biomedical field. This journal is indexed on PubMed Central, MedLine, CAS, SciSearch ${ }^{\circledR}$, Current Contents ${ }^{\circledR} /$ Clinical Medicine,
Journal Citation Reports/Science Edition, EMBase, Scopus and the Elsevier Bibliographic databases. The manuscript management system is completely online and includes a very quick and fair peer-review system, which is all easy to use. Visit http://www.dovepress.com/ testimonials.php to read real quotes from published authors.

Submit your manuscript here: http://www.dovepress.com/international-journal-of-nanomedicine-journal 